\title{
Exposure to L-cycloserine incurs survival costs and behavioral alterations in Aedes aegypti females
}

\author{
Virginia Belloni and Patricia Y Scaraffia ${ }^{*}$
}

\begin{abstract}
Background: It was previously demonstrated that alanine aminotransferase (ALAT, EC 2.6.1.2) participates in maintaining the alanine-proline cycle between flight muscles and fat body during Aedes aegypti flight. ALAT is also actively involved in the metabolism of ammonia in A. aegypti. Here, we investigated the survival and behavioral costs of ALAT inhibition in A. aegypti females to better understand the role of ALAT in blood-fed mosquitoes.

Methods: We analyzed how A. aegypti female mosquitoes respond to blood meals supplemented with $0,2.5,5$ and $10 \mathrm{mM}$ L-cycloserine, a well-known inhibitor of ALAT in animals. Mosquitoes were also exposed to blood meals supplemented with L-cycloserine and different concentrations of glucose $(0,10$ and $100 \mathrm{mM})$. Additionally, the effects of ALAT inhibitor and glucose in mosquitoes starved for 24 or $48 \mathrm{~h}$ were investigated. Survival and behavioral phenotypes were analyzed during a time course $(1,2,4,6,12,24,48$ and $72 \mathrm{~h}$ after feeding).

Results: $\mathrm{L}$-cycloserine at $10 \mathrm{mM}$ resulted in high mortality relative to control, with an acute effect during the first $6 \mathrm{~h}$ after treatment. A significant decrease in the number of active mosquitoes coinciding with an increase in futile wing fanning during the first $24 \mathrm{~h}$ was observed at all inhibitor concentrations. A high occurrence of knockdown phenotype was also recorded at this time for both 5 and $10 \mathrm{mM} \mathrm{L-cycloserine.} \mathrm{The} \mathrm{supplementation} \mathrm{of} \mathrm{glucose} \mathrm{in}$ the blood meal amplified the effects of the ALAT inhibitor. In particular, we observed a higher mortality rate concomitant with an increase in the knockdown phenotype. Starvation prior to blood feeding also increased the effects of L-cycloserine with a rapid increase in mortality.

Conclusions: Our results provide evidence that exposure of high doses of L-cycloserine during A. aegypti blood feeding affects mosquito survival and motor activity, suggesting an interference with carbohydrate and ammonia metabolism in a time-dependent manner.
\end{abstract}

Keywords: Mosquito behavior, Motor activity, Wing fanning, Knockdown response, Mortality, Amino acids, Mosquito metabolism, Survival

\section{Background}

Alanine aminotransferase (ALAT), also called glutamicpyruvic transaminase (EC 2.6.1.2), is responsible for a bimolecular ping-pong reaction, where the $\alpha$-amino group of alanine is transferred to $\alpha$-ketoglutarate, leaving behind pyruvate and glutamate. This reversible reaction synthesizes alanine from pyruvate as well [1]. The enzyme

\footnotetext{
*Correspondence: pscaraff@tulane.edu

Department of Tropical Medicine, Vector-Borne Infectious Disease Research Center, School of Public Health and Tropical Medicine, Tulane University, 1430 Tulane Ave., SL-17, New Orleans, LA 70112, USA
}

contains the prosthetic group pyridoxal phosphate, which acts as a coenzyme in catalytic reactions.

In vertebrates, ALAT activity has been described in several different organisms such as fishes [2], amphibians [3], birds [4], and mammals [5-8]. ALAT is localized to both the cytosol and mitochondria $[8,9]$ and is widely distributed in several organs, with high levels in the liver and kidney [10-12]. In particular, ALAT is expressed in gluconeogenic tissues $[8,13]$. In muscle, the enzyme synthesizes alanine from pyruvate, which is produced by glycolysis. Alanine is shuttled to the liver, where it is converted back to pyruvate and used for gluconeogenesis. The glucose 
produced is then delivered to the muscle to continue the cycle [13]. Moreover, ALAT plays an important role in the brain contributing to its energy supply [14].

In invertebrates, ALAT activity has been observed in crustacea [15], mollusks [16], and several insects, including locusts, tsetse flies, cockroaches, bees, moths [17], and mosquitoes [18]. In some insects, ALAT participates in the metabolism of proline during flight [18-21], and is involved in the metabolism of ammonia [22-24]. In addition, ALAT activity is present in the nervous system of some insects, such as bees $[25,26]$, waterbugs, cockroaches [27] and fruit flies [28], and provides energy to the nerve cells. For example, in the bee's retina, glycogen accumulated in the glia is transferred to the neurons as pyruvate and alanine $[25,26]$.

Over the last few decades, a growing interest has developed in the effects of ALAT inhibition, in both vertebrates and invertebrates. Several potential inhibitors $[2,6,11,29]$ have been tested including $\beta$-chloro-L-alanine [30-32] and L-cycloserine (LCS), an L-isomer of 4-amino3-isoxazolidinone [33]. LCS is one of the ALAT inhibitors most commonly used both in vivo [30,34] and in vitro $[7,11,16,29,30,35]$.

In the present study, we evaluated the potential effects of ALAT inhibition in $A$. aegypti, a widely distributed species of mosquito and a primary vector of viral diseases such as dengue, yellow and chikungunya fever [36]. We investigated how A. aegypti females respond to different concentrations of LCS throughout a period of three days post blood meal, considering behavioral endpoints and mortality as indices of metabolic alterations. We also analyzed the effects of LCS and glucose in nonstarved and starved $A$. aegypti females. The results presented in this manuscript demonstrate that high doses of LCS interfere with A. aegypti blood metabolism causing an impairment of important behavioral phenotypes and a high mortality.

\section{Methods}

\section{Chemicals}

L-cycloserine (LCS), D-glucose (Glc) and sucrose were purchased from Sigma-Aldrich (St. Louis, MO). Bovine blood was obtained from Pel-Freez Biologicals (Rogers, AR).

\section{Insects}

Aedes aegypti (NIH Rockefeller strain, [37]) mosquitoes were reared at standard conditions as previously described [38]. Newly-eclosed mosquitoes were randomly assigned to different containers. Female mosquitoes were fed on 3\% sucrose ad libitum until blood feeding or starved 24 or $48 \mathrm{~h}$ with access to water prior to a blood meal (BM). Mosquitoes were kept in a Caron 6015 Insect Growth Chamber, connected to a Caron CRSY 102 condensate recirculating System (Caron Products \& Services,
Inc., Marietta, $\mathrm{OH}$ ) at $28^{\circ} \mathrm{C}, 75 \%$ relative humidity and a light: dark cycle of $16 \mathrm{~h}: 8 \mathrm{~h}$ until the end of the experiments.

\section{LCS treatments}

Four-day-old female mosquitoes of the same size were allowed to feed for $15 \mathrm{~min}$ on blood meals (see below Treatment 1, 2 and 3) through an artificial blood feeder connected to a $37^{\circ} \mathrm{C}$ water bath [38]. Large groups of female mosquitoes were fed at the same time. After feeding, each female was carefully inspected and only fully engorged mosquitoes were individually transferred to $20 \mathrm{ml}$ polyethylene vials (one female per vial). Each vial was covered with nylon mesh and secured with a rubber band. Mosquitoes were provided water ad libitum throughout the study period and maintained in an Insect Growth Chamber, as described above.

Mosquitoes underwent different experimental treatments:

Treatment 1: BM supplemented with LCS $(0,2.5,5$, $10 \mathrm{mM})$. The experiment was replicated five times with five separate cohorts of mosquitoes, with a total sample size of 250 for each concentration.

Treatment 2: BM supplemented with LCS $(0,10 \mathrm{mM})$ and Glc $(0,10,100 \mathrm{mM})$. All the combinations of LCS and Glc were tested. The experiment was replicated three times with three separate cohorts of mosquitoes, with a total sample size of 75 for each concentration. Treatment 3: mosquitoes were starved for 24 or $48 \mathrm{~h}$ prior to the BM supplemented with LCS $(0,10 \mathrm{mM})$ and Glc $(0,100 \mathrm{mM})$. All the combinations of LCS and Glc were tested. The experiments were replicated three times with three separate cohorts of mosquitoes, with a total sample size of 75 for each concentration.

\section{Mortality and behavioral phenotypes}

During a $15 \mathrm{sec}$ window, mortality rate and behavioral observations were recorded at $1,2,4,6,12$ (only in Treatment 1 ), 24, 48 and $72 \mathrm{~h}$ post blood meal (PBM).

Presence or absence of the following behavioral endpoints was individually scored:

- Active: mosquito shows normal behavior such as proper coordination and the ability to stand, walk, and fly.

- Wing fanning: mosquito shows a persistent wing fanning behavior in a futile attempt to fly. Wing fanning was previously described in other insects (reviewed in Haynes, 1988 [39]). It can be accompanied by loss of coordination.

- Knockdown: mosquito shows inability to stand, walk or fly, according to the ethological profile described in mosquitoes $[40,41]$. 
In this manuscript the terms wing fanning and knockdown refer to impaired motor activity.

\section{Statistical analysis}

Survival analysis was performed using Log-rank and TaroneWare tests. Bonferroni correction was applied when multiple comparisons were performed. The analysis was carried out using GraphPad Prism version 6.0 for Mac OS X (GraphPad Software, San Diego, CA). Behavior was categorized into three levels (active, wing fanning and knockdown). Generalized estimating equation (GEE) regression methods were used to examine the impact of treatment, and any interaction with time, on behavior. Behavioral data were analyzed using PROC GENMOD, SAS version 9.3 (SAS Institute Inc., Cary, NC) with a cumulative logit link and an independent correlation structure. A $p$-value less than 0.05 was considered significant. Data are presented as mean \pm standard error (SE).

\section{Results}

\section{LCS impairs motor activity and survival}

To better understand the role of ALAT in blood-fed $A$. aegypti metabolism, we experimentally assessed the survival costs of LCS-dependent inhibition in A. aegypti females and analyzed their behavioral phenotypes during 3 days post treatment. This was done by comparing outcomes between mosquitoes that were fed a BM (control group) and mosquitoes fed BM's with LCS at varying concentrations (Treatment 1 ).

As shown in Figure 1, only $5(2 \% \pm 1)$ of the individuals fed with blood alone (BM) died during the $72 \mathrm{~h}$ of observation, while mosquitoes exposed to $10 \mathrm{mM}$ LCS $(\mathrm{BM}+10 \mathrm{mM} \mathrm{LCS})$ had a significantly higher mortality $(35 \% \pm 6)$ [Log-Rank, $\chi_{3}^{2}=259.2, p=0.0001$ ] than the other three groups $(\mathrm{BM}=2 \% \pm 1 ; \mathrm{BM}+2.5 \mathrm{mM} \mathrm{LCS}=$ $0.4 \% \pm 0.4 ; \quad \mathrm{BM}+5 \mathrm{mM} \quad \mathrm{LCS}=2 \% \pm 1)$. Moreover, at $10 \mathrm{mM}$ LCS most mortality occurred within the first hours PBM, reaching $24 \%$ by $6 \mathrm{~h}$, while only $11 \%$ of the mosquitoes died between day 1 and day 3 . No difference in mortality was observed among the other groups of this treatment [Log-Rank, $\mathrm{X}_{2}^{2}=3.55, p=0.17$ ].

When we examined behavioral phenotypes (Figure 1; Additional file 1: Video S1) of all four groups, motor activity was impaired in a time-dependent manner by LCS administration [GEE, Time, $\chi_{1}^{2}=507.24, \quad p=0.0001$ ], resulting in a greater occurrence of wing fanning and knockdown behavior relative to control. The LCS effect was dose-dependent, where the number of active mosquitoes decreased with the increase of LCS concentration accompanied by a higher probability of knockdown response [GEE, Dose, $\left.X^{2}{ }_{1}=273.54, p=0.0001\right]$. Wing fanning was observed at all LCS concentrations, while knockdown was almost absent at $2.5 \mathrm{mM}$ LCS (Figure 1A-D; Additional file 2: Table S1). Impairment of motor activity

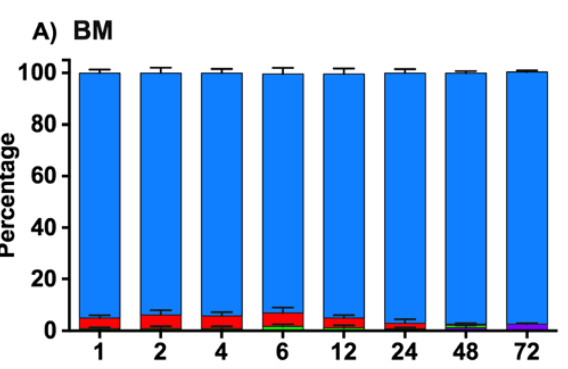

B) $\mathrm{BM}+2.5 \mathrm{mM} \mathrm{LCS}$

C) $\mathrm{BM}+5 \mathrm{mM}$ LCS
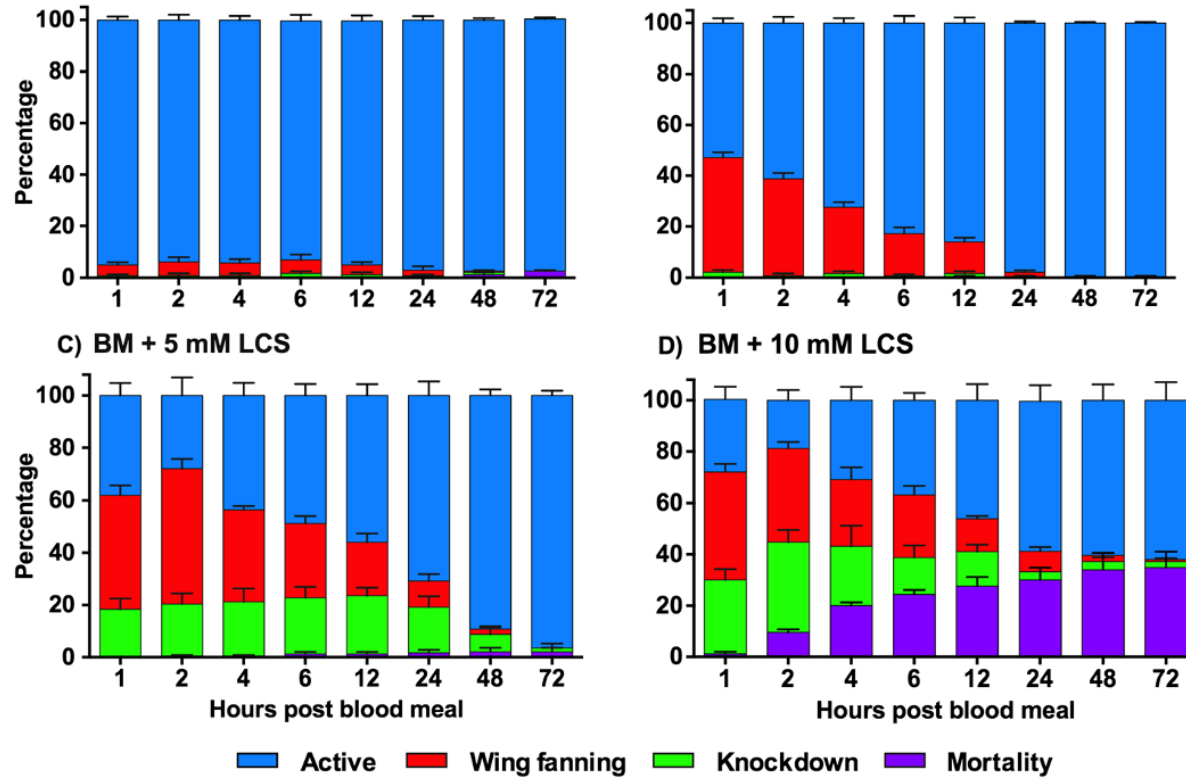

D) $\mathrm{BM}+10 \mathrm{mM}$ LCS

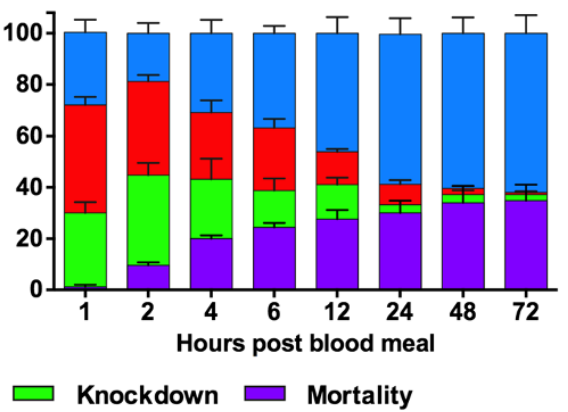

Figure 1 Effect of LCS on the behavioral phenotypes and mortality in A. aegypti. A) BM; B) BM $+2.5 \mathrm{mM} \mathrm{LCS;} \mathrm{C)} \mathrm{BM}+5$ mM LCS; D) BM + 10 mM LCS. BM: blood meal; LCS: L-cycloserine. Female mosquitoes were fed a blood meal supplemented with different concentrations of LCS $(0,2.5,5$ and $10 \mathrm{mM})$. Data are expressed as mean percentage $\pm \mathrm{SE}$. 
occurred within the first hours PBM. However, a clear recovery was observed over time (Figure 1B-D).

\section{LCS and Glc increase the behavioral response and mortality}

Since pyruvate required for transamination can be produced by the oxidation of Glc, we speculated that the effects of LCS on mosquitoes would be modified in the presence of Glc. To determinate whether Glc alters the effects of LCS on mosquitoes, we investigated the survival costs of the ALAT inhibitor in A. aegypti females after they were provided blood meals supplemented with LCS and Glc (Treatment 2). As with Treatment 1, we evaluated their behavioral responses during $72 \mathrm{~h}$ PBM.

During the course of the experiment no mosquitoes died in the groups exposed to $\mathrm{BM}+10 \mathrm{mM}$ Glc or BM + $100 \mathrm{mM}$ Glc when compared to BM (Figure 2). When the effect of $10 \mathrm{mM}$ LCS was tested, mortality was significantly higher than in the BM control [Log-Rank, $\mathrm{X}^{2}{ }_{3}=$ 89.76, $p<0.0001$; BM: $4 \% \pm 2$; BM +10 mM LCS: $52 \% \pm 0$; $\mathrm{BM}+10 \mathrm{mM}$ LCS $+10 \mathrm{mM}$ Glc: $77 \% \pm 7 ; \mathrm{BM}+10 \mathrm{mM}$ LCS $+100 \mathrm{mM}$ Glc: $67 \% \pm 7$ ] (Figure 2). In the presence of Glc, the effect of LCS increased [Log-Rank, $\chi^{2}{ }_{2}=12.37$, $p=0.0021 ; \mathrm{BM}+10 \mathrm{mM}$ LCS; $\mathrm{BM}+10 \mathrm{mM} \mathrm{LCS}+$ $10 \mathrm{mM}$ Glc; BM + $10 \mathrm{mM} \mathrm{LCS}+100 \mathrm{mM}$ Glc], reducing the population by half at $4 \mathrm{~h}$ PBM. When $\mathrm{BM}+10 \mathrm{mM}$ $\mathrm{LCS}+10 \mathrm{mM}$ Glc and BM + $10 \mathrm{mM} \mathrm{LCS}+100 \mathrm{mM}$ Glc were compared, no dose-dependent effect was observed (Figure 2).

As shown in Figure 2A-C, no difference in the behavioral phenotypes was observed among the $\mathrm{BM}, \mathrm{BM}+10 \mathrm{mM}$ Glc and BM + 100 mM Glc groups, while LCS significantly affected mosquito activity in a time-dependent way [GEE, Time, $\left.\chi^{2}{ }_{1}=40.61, p=0.0001\right]$. When we compared the effect of the inhibitor under Glc supplementation $(0,10$ and $100 \mathrm{mM}$ ), Glc decreased the probability of active behavior [GEE, Dose Glc: $\left.\mathrm{X}_{2}^{2}=34.39, p=0.0001\right]$ due to an increase of knockdown response (Figure 2). However, the effect was independent from the Glc concentration (Additional file 3: Table S2), and over time BM + $10 \mathrm{mM} \mathrm{LCS} \mathrm{+} 100 \mathrm{mM}$ Glc group recovered, reaching a number of active mosquitoes similar to $B M+10 \mathrm{mM}$ LCS group. A slight recovery was observed in BM + $10 \mathrm{mM} \mathrm{LCS} \mathrm{+} 10 \mathrm{mM}$ Glc group [GEE, Time*Dose Glc: $\mathrm{X}^{2}{ }_{2}=14.64, p=0.0007$; Figure 2D-F] .

\section{Starvation prior to LCS-treatment severely increases the LCS effects}

It is well known that starvation mobilizes the nutritional reserves in both vertebrates and invertebrates. To explore whether starvation impacts the phenotypes observed after LCS treatment, we tested the survival costs of the ALAT inhibitor on mosquitoes starved for 24 or $48 \mathrm{~h}$ (Treatment 3). We also examined their behavioral responses during 3 days post treatment.
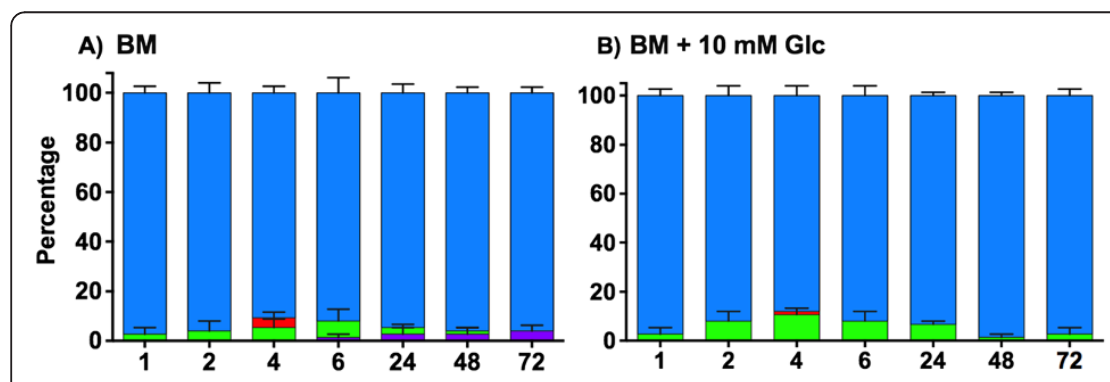

D) $\mathrm{BM}+10 \mathrm{mM}$ LCS

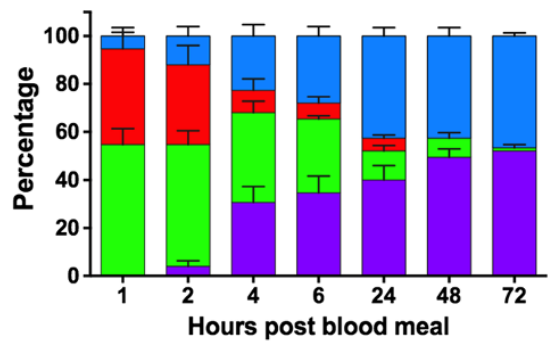

E) $B M+10 \mathrm{mM} \mathrm{LCS}+10 \mathrm{mM}$ Glc

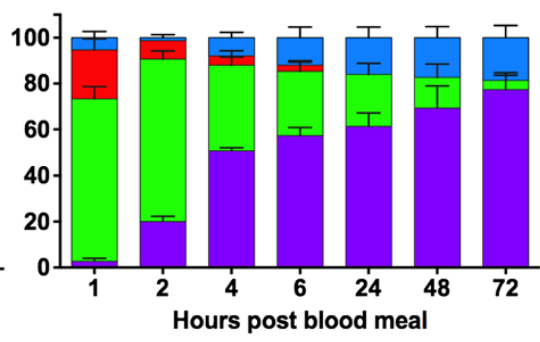

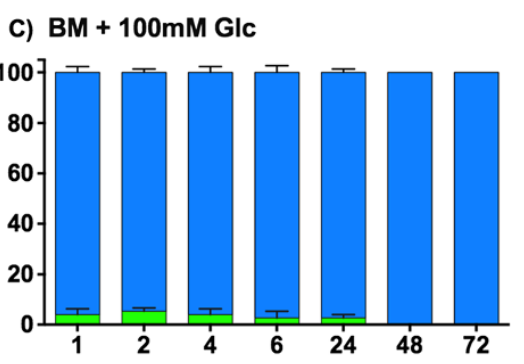

F) $B M+10 \mathrm{mM} \mathrm{LCS}+100 \mathrm{mM} \mathrm{Glc}$

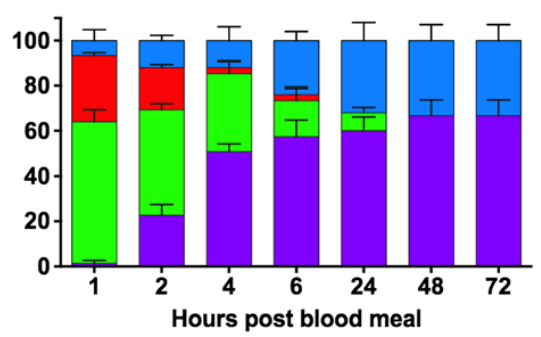

Mortality

Figure 2 Effect of LCS and Glc on the behavioral phenotypes and mortality in A. aegypti. A) BM; B) BM + $10 \mathrm{mM} \mathrm{Glc;C)} \mathrm{BM+100} \mathrm{mM}$ Glc; D) BM + 10 mM LCS; E) BM + 10 mM LCS + 10 mM Glc; F) BM + 10 mM LCS + 100 mM Glc. BM: blood meal; LCS: L-cycloserine; Glc: glucose. Female mosquitoes were fed a blood meal supplemented with different concentrations of LCS $(0,10 \mathrm{mM})$ and Glc $(0,10,100 \mathrm{mM})$. Data are expressed as mean percentage \pm SE. 
Starvation for $24 \mathrm{~h}$ significantly affected mosquito survival in the presence of LCS $(B M+10 \mathrm{mM} \mathrm{LCS}$ : $93 \% \pm 1$; $\mathrm{BM}+10 \mathrm{mM}$ LCS $+100 \mathrm{mM}$ Glc: $76 \% \pm 2$ ) relative to the control groups (BM: $3 \% \pm 3$; $\mathrm{BM}+100 \mathrm{mM}$ Glc: $3 \% \pm 3$ ) [Tarone-Ware, $X_{3}^{2}=219.1, p<0.0001$ ] (Figure 3). Although a similar trend was observed in LCS-treated groups, the rate of mortality increased faster in the presence of Glc during the first $24 \mathrm{~h}$, where $50 \%$ mortality was reached by $4 \mathrm{~h}$ PBM. The effect was stronger later in the absence of Glc with a higher total mortality at $72 \mathrm{~h}$ PBM (Figure 3).

As shown in Figure 3 and Additional file 4: Table S3, the high mortality rate in LCS groups was associated with a reduced number of active mosquitoes and a greater knockdown response, compared to control groups (BM and BM+

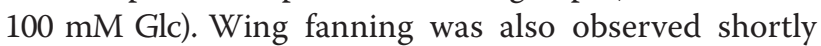
after feeding in LCS groups. Time was not a significant factor [GEE, Time: $\chi^{2}{ }_{1}=0.01, p=0.9$ ] with few active mosquitoes in the LCS groups. However, Glc supplementation resulted in a higher probability of active behavior and lower knockdown response associated with a greater percentage of survival [GEE, Treatment Glc, $\chi^{2}{ }_{1}=$ 13.73, $p=0.0002$; Time ${ }^{*}$ Treatment Glc, $\chi^{2}{ }_{1}=5.04, p=$ 0.0248; Figure 3C-D].

When mosquitoes were starved for $48 \mathrm{~h}$ prior to blood feeding (Figure 4), a similar response pattern to $24 \mathrm{~h}$ starvation was observed; LCS treatment resulted in significant mortality $(\mathrm{BM}+10 \mathrm{mM}$ LCS: $96 \% \pm 4 ; \mathrm{BM}+$ $10 \mathrm{mM}$ LCS $+100 \mathrm{mM}$ Glc: $100 \%)$ compared to the control groups (BM: $11 \% \pm 1 ; \mathrm{BM}+100 \mathrm{mM}$ Glc: $3 \% \pm 1$ ) [Log-Rank, $\left.\mathrm{X}_{3}^{2}=319.9, p<0.0001\right]$, with a faster increase in the mortality rate in the first $24 \mathrm{~h} \mathrm{PBM}$ in the presence of Glc (median survival $=2 \mathrm{~h}$ PBM).

The LCS-treated groups showed a low occurrence of active behavior and a high occurrence of knockdown response, which reached its highest level within the first hours PBM with respect to the groups not exposed to LCS (Figure 4 and Additional file 5: Table S4). Furthermore, the same mosquitoes showed wing fanning behavior only shortly after feeding (1-2 h) (Additional file 5: Table S4). When the effect of Glc was considered (BM + $10 \mathrm{mM} \mathrm{LCS} \mathrm{+} 100 \mathrm{mM}$ Glc), no recovery was observed. In absence of Glc (BM + 10 mM LCS), LCS-survived mosquitoes recovered slightly over time [GEE, Treatment Glc, $\chi^{2}{ }_{1}=17.39, p<0.0001$; Time ${ }^{*}$ Treatment Glc, $\chi^{2}{ }_{1}=11.75$, $p=0.0006$; Figure 4C-D].

\section{Discussion}

Alanine aminotransferase (ALAT) plays an important role in maintaining the alanine-proline cycle between flight muscles and fat body during $A$. aegypti flight [18]. Additionally, the ALAT enzyme responds efficiently when $A$. aegypti mosquitoes face an ammonia challenge [22-24]. Thus, any interference with ALAT activity could compromise the efficiency of the pathways involved in ammonia metabolism [22-24,38,42], resulting in deleterious effects on blood-fed $A$. aegypti females. In the study performed here, we treated $A$. aegypti

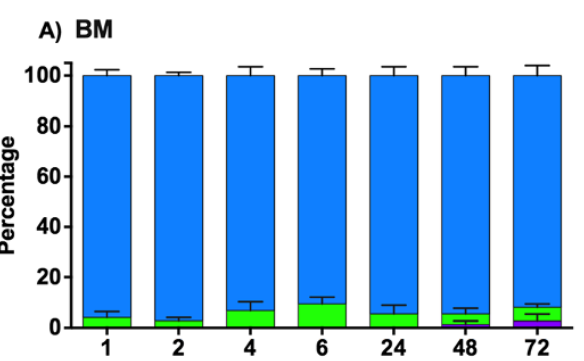

B) $\mathrm{BM}+100 \mathrm{mM} \mathrm{Glc}$

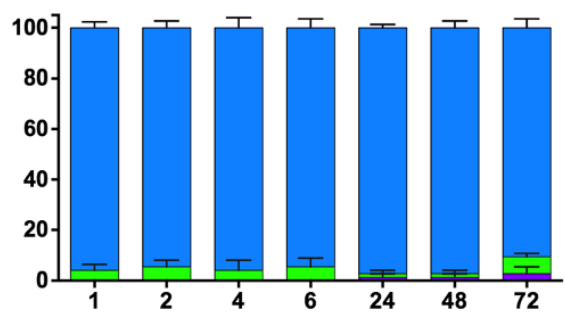

C) $\mathrm{BM}+10 \mathrm{mM}$ LCS

D) $\mathrm{BM}+10 \mathrm{mM} \mathrm{LCS}+100 \mathrm{mM}$ Glc
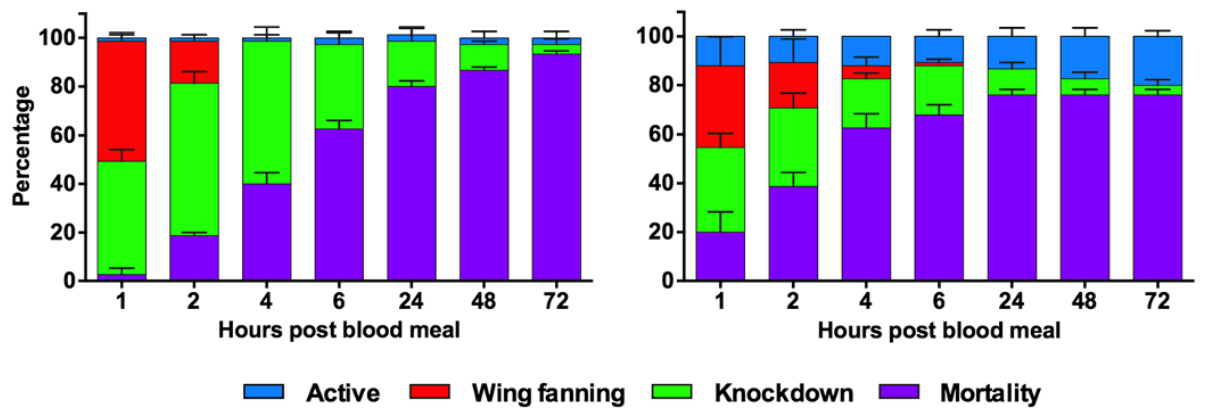

Figure 3 Effect of LCS on the behavioral phenotypes and mortality in 24 h starved A. aegypti. A) BM; B) BM + 100 mM Glc; C) BM + 10 mM LCS; D) BM + 10 mM LCS + 100 mM Glc. BM: blood meal; LCS: L-cycloserine; Glc: glucose. Female mosquitoes were starved for 24 h prior to the administration of a blood meal supplemented with LCS (0, $10 \mathrm{mM})$ and Glc $(0,100 \mathrm{mM})$. Data are expressed as mean percentage \pm SE. 


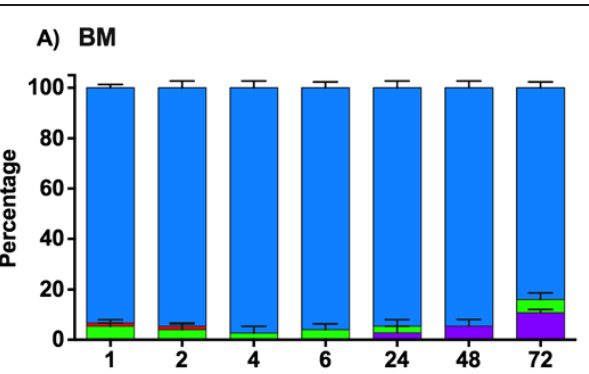

C) $\mathrm{BM}+10 \mathrm{mM}$ LCS

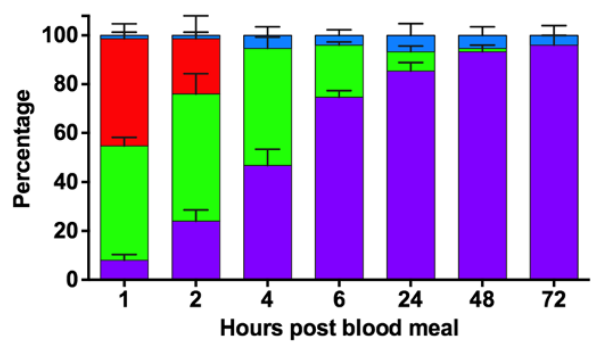

B) $\mathrm{BM}+100 \mathrm{mM} \mathrm{Glc}$

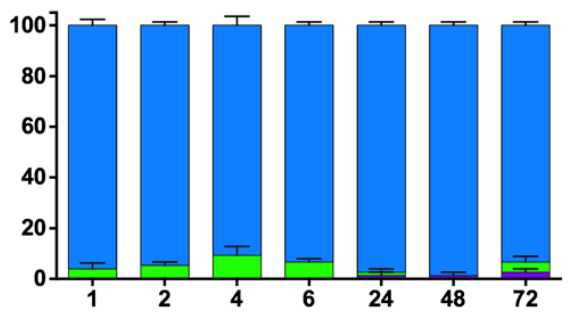

D) $\mathrm{BM}+10 \mathrm{mM} \mathrm{LCS}+100 \mathrm{mM}$ Glc

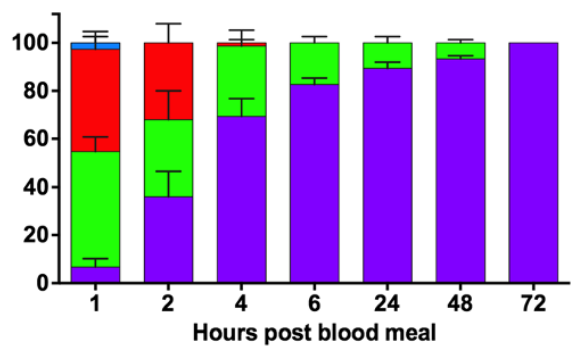

$\square$ Active $\square$ Wing fanning

Knockdown Mortality

Figure 4 Effect of LCS on the behavioral phenotypes and mortality in $\mathbf{4 8} \mathbf{h}$ starved $\boldsymbol{A}$. aegypti. A) BM; B) BM + $100 \mathrm{mM} \mathrm{Glc;} \mathrm{C)} \mathrm{BM+10} \mathrm{mM}$ LCS; D) BM + 10 mM LCS + 100 mM Glc. BM: blood meal; LCS: L-cycloserine; Glc: glucose. Female mosquitoes were starved for $48 \mathrm{~h}$ prior to the administration of a blood meal supplemented with $\mathrm{LCS}(0,10 \mathrm{mM})$ and $\mathrm{Glc}(0,100 \mathrm{mM})$. Data are expressed as mean percentage \pm SE.

mosquitoes with L-cycloserine (LCS), a well-known inhibitor of ALAT.

In animals, LCS is able to strongly or completely inhibit ALAT activity $[7,11,16,29,30,34]$. When increasing concentrations of LCS $(0,2.5,5$ and $10 \mathrm{mM})$ in blood meals were tested in A. aegypti females (Treatment 1, Methods Section), only the highest dose affected female survival with an acute effect during the first hours post treatment. However, motor behavior was affected in all the LCS-groups following a time-dependent pattern with a clear recovery over time. All three concentrations of LCS showed a high occurrence of wing fanning, but only 5 and $10 \mathrm{mM}$ LCS were associated with a significant number of mosquitoes exhibiting the knockdown behavior. Mortality was observed only at $10 \mathrm{mM}$ LCS, suggesting a dose-dependent increase in the severity of the motor disruption with death as the ultimate impairment. Interestingly, the addition of glucose into blood meals (Treatment 2, Methods Section) or starvation (Treatment 3, Methods Section) increased the LCS effects on mosquitoes. Our data also indicate that behavioral endpoints are a useful tool to investigate the effect of enzymatic inhibitors able to interfere with mosquito metabolism. Motor activity impairment caused by the exposure to chemicals in natural conditions could result in a compromised seeking and biting behavior, and therefore affect disease transmission $[43,44]$.

In LCS-blood fed $A$. aegypti (Treatments with $10 \mathrm{mM}$ LCS), the early peak observed in both mortality and impaired behavior suggests that LCS strongly interacts with ALAT soon after blood feeding. Early LCS response was also described in rats, where inhibition of ALAT activity rapidly reached a peak merely 30-60 minutes post LCS injection [34]. One hour LCS-perfusion also resulted in a fast decrease of ALAT in rats [45]; whereas in mice an intra-peritoneal injection of the inhibitor affected ALAT and induced a moderate impairment of motor performance three hours after administration [46]. The recovery observed in surviving LCS-blood fed mosquitoes might indicate that the inhibitor acts rapidly on tissues, but somehow it is then detoxified or removed from the system. The underlying mechanisms of mosquito recovery are unknown at the present. However, it is possible that the surviving mosquitoes use alternative pathways to deal with ALAT inhibition, as previously reported in blood-fed $A$. aegypti females when glutamine synthetase was silenced by specific inhibitors [22-24].

The phenotypes described here in A. aegypti mosquitoes treated with high doses of LCS could be associated with an alteration of ammonia metabolic pathways. In $A$. aegypti, inhibition of enzymes involved in fixation and assimilation phases of ammonia metabolism [22-24] resulted in a high mortality, preceded by the suppression of locomotor activity [24]. In mammals, an excess of ammonia in the brain affected the activity of neurotransmitters involved in the regulation of motor activity such as acetylcholine [47], glutamate and its product $\gamma$-aminobutyric acid [48-50]. High levels of ammonia in neuronal and other 
tissues have been associated with deleterious effects and death in several animal species [48,51-53] owing to an increase in oxidative stress, energy deficiency, and alteration of neurotransmission systems in a concentration and time-dependent manner $[48,51,54]$. Recently, Beuster et al., [30] found that ALAT inhibition with LCS correlates with several alterations in mammalian cancer cells, such as energy deficiency, increased respiration rates, and mitochondrial production of reactive oxygen species. Moreover, inhibition of ALAT by LCS was associated with a decrease in glucose uptake, and thus a suppression of the overall glucose metabolism in rodent cell lines [30]. In A. aegypti mosquitoes, sugar feeding plays an important role in the metabolism of amino acids and energy supply [55]. In Treatment 2, all the LCS-groups showed a similar time-dependent pattern associated with recovery over time, although lower in the presence of glucose. The severity of LCS effects after glucose supplementation observed here correlates closely with a disruption of glucose and amino acid metabolism in $A$. aegypti females. It could be interesting to explore whether any of these cellular effects caused by LCS in vertebrates can be also correlated to the behavioral alterations observed in mosquitoes treated with the higher doses of LCS.

In $A$. aegypti, starvation strongly impacts energy supply and results in low flight potential [56]. Moreover, when $A$. aegypti are sugar-starved for $24 \mathrm{~h}$ prior to feeding on a protein meal, proline and alanine levels are significantly increased relative to the level of non-starved mosquitoes [57]. In rodents, $48 \mathrm{~h}$ starvation induces an increase in alanine production, while alanine release is decreased by LCS perfusion [58]. These findings could support how starvation can result in the greater mortality and behavioral alterations observed in $A$. aegypti mosquitoes exposed to ALAT inhibitor. The LCS administration induced a rapid increase in mortality in $A$. aegypti females starved for $24 \mathrm{~h}$. The effect was amplified in females starved for $48 \mathrm{~h}$. In addition, the supplementation of glucose resulted in a faster increase in the mortality, but only in the first $4 \mathrm{~h}$ post treatment. Finally, a slight recovery and reduced number of knockdown phenotype occurred in the presence of glucose in mosquito females starved for $24 \mathrm{~h}$, while no recovery was observed in females starved for $48 \mathrm{~h}$.

Despite high specificity of LCS for ALAT, it is known that LCS can interact with other transaminases in animals $[11,34,46]$. Therefore, we cannot exclude the possible side effects of the LCS treatment on additional targets in mosquitoes. To overcome this problem, we are currently investigating the effects of silencing ALAT in A. aegypti females through RNA interference.

\section{Conclusion}

This study demonstrates that exposure to high LCS doses incurs survival costs and behavioral alterations in
A. aegypti females. The LCS effects were amplified when mosquito blood meals were supplemented with glucose or when females were starved prior to blood feeding. Taken together, our data suggest that LCS interferes with carbohydrate and ammonia metabolism in a time-dependent manner in blood-fed A. aegypti females.

\section{Additional files}

\begin{abstract}
Additional file 1: Video S1. Effect of LCS on wing fanning behavior in an A. aegypti female. Mosquito behavior was video recorded in an A. aegypti female exposed to a blood meal supplemented with LCS (10 mM). The observation was recorded at $4 \mathrm{~h}$ post blood meal.
\end{abstract}

Additional file 2: Table S1. Comparison of behavioral phenotypes in A. aegypti exposed to $\operatorname{LCS}(0,2.5,5$ and $10 \mathrm{mM}$ ) (Treatment 1, Methods Section). Data are expressed as mean percentage ( \pm SE) calculated from the surviving mosquitoes.

Additional file 3: Table S2. Comparison of behavioral phenotypes in A. aegypti exposed to LCS $(0,10 \mathrm{mM})$ and $\mathrm{Glc}(0,10,100 \mathrm{mM})$ (Treatment 2, Methods Section). Data are expressed as mean percentage $( \pm \mathrm{SE})$ calculated from the surviving mosquitoes.

Additional file 4: Table S3. Comparison of behavioral phenotypes in A. aegypti starved for $24 \mathrm{~h}$ and exposed to $\operatorname{LCS}(0,10 \mathrm{mM})$ and $\mathrm{GlC}$ $(0,100 \mathrm{mM})$ (Treatment 3, Methods Section). Data are expressed as mean percentage $( \pm \mathrm{SE})$ calculated from the surviving mosquitoes.

Additional file 5: Table S4. Comparison of behavioral phenotypes in A. aegypti starved for $48 \mathrm{~h}$ and exposed to LCS $(0,10 \mathrm{mM})$ and $\mathrm{GlC}(0$, 100 mM) (Treatment 3, Methods Section). Data are expressed as mean percentage $( \pm \mathrm{SE})$ calculated from the surviving mosquitoes.

\section{Abbreviations}

ALAT: Alanine aminotransferase; LCS: L-cycloserine; Glc: Glucose; BM: Blood meal; PBM: Post blood meal.

\section{Competing interests}

The authors declare that they have no competing interests.

\section{Authors' contributions}

Conceived and designed the experiment: PYS. Performed the experiments: VB, PYS. Analyzed the data: VB, PYS. Wrote the paper: VB, PYS. Both authors read and approved the final version of the manuscript.

\section{Acknowledgments}

The authors would like to thank Dr. Stacy Mazzalupo for her critical reading of the manuscript and valuable comments. This work was financially supported by National Institutes of Health (NIH) grant R01Al088092 to PYS.

Received: 3 March 2014 Accepted: 17 July 2014

Published: 16 August 2014

\section{References}

1. Berg JM, Tymoczko JL, Stryer L: The first step in amino acid degradation is the removal of nitrogen. In Biochemistry. 5th edition. New York: Freeman WH; 2002. Series 23.23.

2. González JD, Caballero A, Viegas I, Metón I, Jones JG, Barra J, Fernández F, Baanante IV: Effects of alanine aminotransferase inhibition on the intermediary metabolism in Sparus aurata through dietary aminooxyacetate supplementation. Br J Nutr 2011, 107:1747-1756.

3. Alekhova T, Sof'in A, Kobelkova T, Marco R, Dournon C: Sex-linked differences in activity of enzymes in the blood of the urodele amphibian Pleurodeles waltl. Comp Biochem Physiol A Mol Integr Physiol 2001, 130:819-825.

4. Polo FJ, Peinado VI, Viscor G, Palomeque J: Hematologic and plasma chemistry values in captive Psittacine birds. Avian Dis 1998, 42:523-535.

5. Rajamohan F, Nelms L, Joslin DL, Lu B, Reagan WJ, Lawton M: cDNA cloning, expression, purification, distribution, and characterization of 
biologically active canine alanine aminotransferase-1. Protein Expr Purif 2006, 48:81-89.

6. Pan M, Souba WW, Wolfgang CL, Karinch AM, Stevens BR: Posttranslational Alanine trans-stimulation of zwitterionic amino acid transport systems in human Intestinal Caco-2 cells. J Surg Res 2002, 104:63-69.

7. LaNoue KF, Berkich DA, Conway M, Barber AJ, Hu LY, Taylor C, Hutson S: Role of specific aminotransferases in de novo glutamate synthesis and redox shuttling in the retina. J Neurosci Res 2001, 66:914-922.

8. De Rosa G, Swick RW: Metabolic implications of the distribution of the alanine aminotransferase isoenzymes. J Biol Chem 1975, 250:7961-7967.

9. Metón I, Egea M, Fernández F, Eraso MC, Baanante IV: The N-terminal sequence directs import of mitochondrial alanine aminotransferase into mitochondria. FEBS Lett 2004, 566:251-254.

10. Yang RZ, Blaileanu G, Hansen BC, Shuldiner AR, Gong DW: cDNA cloning, genomic structure, chromosomal mapping, and functional expression of a novel human alanine aminotransferase. Genomics 2002, 79:445-450.

11. Cornell NW, Zuurendonk PF, Kerich MJ, Straight CB: Selective inhibition of alanine aminotransferase and aspartate aminotransferase in rat hepatocytes. Biochem J 1984, 220:707-716.

12. Kamoda N, Minatogawa Y, Nakamura M, Nakanishi J, Okuno E, Kido R: The organ distribution of human alanine-2-oxoglutarate aminotransferase and alanine-glyoxylate aminotransferase. Biochem Med 1980, 23:25-34.

13. Felig P, Pozefsk T, Marlis E, Cahill GF Jr: Alanine: key role in gluconeogenesis. Science 1970, 167:1003-1004.

14. Bhattacharya SB, Datta AG: Is brain a gluconeogenic organ? Mol Cell Biochem 1993, 125:51-57

15. Chien $\mathrm{YH}$, Pan $\mathrm{CH}$, Hunter $\mathrm{B}$ : The resistance to physical stresses by Penaeus monodon juveniles fed diets supplemented with astaxanthin. Aquaculture 2003, 216:177-191.

16. Paynter KT, Ellis LL, Bishop SH: Cellular location and partial characterization of the alanine aminotransferase in ribbed mussel gill tissue. J Exp Zool 1984, 232:51-58.

17. Crabtree B, Newsholme EA: The activities of proline dehydrogenase, glutamate dehydrogenase, aspartate-oxoglutarate aminotransferase and alanine-oxoglutarate aminotransferase in some insect flight muscles. Biochem J 1970, 117:1019-1021.

18. Scaraffia PY, Wells MA: Proline can be utilized as an energy substrate during flight of Aedes aegypti females. J Insect Physiol 2003, 49:591-601.

19. Gäde $G$, Auerswald L: Flight substrates and their regulation by a member of the AKH/RPCH family of neuropeptides in Cerambycidae. J Insect Physiol 2000, 46:1575-1584.

20. Weeda E, De Kort CAD, Beenakkers AMT: Oxidation of proline and pyruvate by flight muscle mitochondria of the Colorado beetle, Leptinotarsa decemlineata say. Insect Biochem 1980, 10:305-311.

21. Bursell $E$ : Aspects of the flight metabolism of tsetse flies (Glossina). Comp Biochem Physiol 1966, 19:809-818.

22. Scaraffia PY, Zhang Q, Thorson K, Wysocki VH, Miesfeld RL: Differential ammonia metabolism in Aedes aegypti fat body and midgut tissues. J Insect Physiol 2010, 56:1040-1049.

23. Scaraffia PY, Zhang Q, Wysocki VH, Isoe J, Wells MA: Analysis of whole body ammonia metabolism in Aedes aegypti using $\left[{ }^{15} \mathrm{~N}\right]$-labeled compounds and mass spectrometry. Insect Biochem Mol Biol 2006, 36:614-622.

24. Scaraffia PY, Isoe J, Murillo A, Wells MA: Ammonia metabolism in Aedes aegypti. Insect Biochem Mol Biol 2005, 35:491-503.

25. Coles JA, Martiel JL, Laskowska K: A glia-neuron alanine/ammonium shuttle is central to energy metabolism in bee retina. J Physio/ 2008 , 586:2077-2091.

26. Tsacopoulos M, Veuthey AL, Saravelos SG, Perrottet P, Tsoupras G: Glial cells transform glucose to alanine, which fuels the neurons in the honeybee retina. J Neurosci 1994, 14:1339-1351.

27. Sugden $\mathrm{PH}, \mathrm{Newsholme} \mathrm{EA:} \mathrm{Activities} \mathrm{of} \mathrm{citrate} \mathrm{synthase,} \mathrm{NAD} \mathrm{+} \mathrm{-linked} \mathrm{and}$ NADP + -linked isocitrate dehydrogenases, glutamate dehydrogenase, aspartate aminotransferase and alanine aminotransferase in nervous tissues from vertebrates and invertebrates. Biochem J 1975, 150:105-111.

28. Schneider M, Chen PS: L-Alanine aminotransferase in Drosophila nigromelanica: isolation, characterization and activity during ontogenesis. Insect Biochem 1981, 11:657-673.

29. De Rosa G, Burk TL, Swick RW: Isolation and characterization of mitochondrial alanine aminotransferase from porcine tissue. Biochim Biophys Acta 1979, 567:116-124.
30. Beuster G, Zarse K, Kaleta C, Thierbach R, Kiehntopf M, Steinberg P, Schuster $\mathrm{S}$, Ristow M: Inhibition of alanine aminotransferase in silico and in vivo promotes mitochondrial metabolism to impair malignant growth. J Biol Chem 2011, 286:22323-22330.

31. Golichowski A, Jenkins WT: Inactivation of pig heart alanine aminotransferase by $\beta$-chloroalanine. Arch Biochem Biophys 1978, 189:109-114.

32. Morino $Y$, Tanase $S$ : Chemical structure of the active site of pig heart mitochondrial aspartate aminotransferase labeled with beta-chloro-l-alanine. J Biol Chem 1978, 253:252-256.

33. Chung $\mathrm{SH}$, Johnson MS, Gronenborn AM: L-Cycloserine: a potent anticonvulsant. Epilepsia 1984, 25:353-362.

34. Wong DT, Fuller RW, Molloy BB: Inhibition of amino acid transaminases by L-cycloserine. Adv Enzyme Regul 1973, 11:139-154.

35. Wale PL, Gardner DK: Oxygen affects the ability of mouse blastocysts to regulate ammonium. Biol Reprod 2013, 89:1-10.

36. Morrison AC, Zielinski-Gutierrez E, Scott TW, Rosenberg R: Defining challenges and proposing solutions for control of the virus vector Aedes aegypti. PLoS Med 2008, 5:e68.

37. Kuno G: Early history of laboratory breeding of Aedes aegypti (Diptera: Culicidae) focusing on the origins and use of selected strains. J Med Entomol 2010, 47:957-971.

38. Isoe J, Scaraffia PY: Urea synthesis and excretion in Aedes aegypti mosquitoes are regulated by a unique cross-talk mechanism. PLoS One 2013, 8:e65393.

39. Haynes KF: Sublethal effects of neurotoxic insecticides on insect behavior. Annu Rev Entomol 1988, 33:149-168.

40. Ritchie SA, Devine GJ: Confusion, knock-down and kill of Aedes aegypti using metofluthrin in domestic settings: a powerful tool to prevent dengue transmission? Parasit Vectors 2013, 6:262-280.

41. Achee N, Masuoka P, Smith P, Martin N, Chareonviryiphap T, Polsomboon S, Hendarto J, Grieco J: Identifying the effective concentration for spatial repellency of the dengue vector Aedes aegypti. Parasit Vectors 2012, 5:300.

42. Scaraffia PY, Tan G, Isoe J, Wysocki VH, Wells MA, Miesfeld RL: Discovery of an alternate metabolic pathway for urea synthesis in adult Aedes aegypti mosquitoes. Proc Natl Acad Sci U S A 2008, 105:518-523.

43. Achee NL, Bangs MJ, Farlow R, Killeen GF, Lindsay S, Logan JG, Moore SJ, Rowland M, Sweeney K, Torr SJ, Zwiebel LJ, Grieco JP: Spatial repellents: from discovery and development to evidence-based validation. Malar $J$ 2012, 11:164.

44. Ogoma SB, Moore SJ, Maia MF: A systematic review of mosquito coils and passive emanators: defining recommendations for spatial repellency testing methodologies. Parasit Vectors 2012, 5:287.

45. Dawson KD, Baker DJ, Greenhaff PL, Gibala MJ: An acute decrease in TCA cycle intermediates does not affect aerobic energy delivery in contracting rat skeletal muscle. J Physiol 2005, 565:637-643.

46. Polc P, Pieri L, Bonetti EP, Scherschlicht R, Moehler H, Kettler R, Burkard W, Haefely W: L-Cycloserine: behavioural and biochemical effects after single and repeated administration to mice, rats and cats. Neuropharmacology 1986, 25:411-418.

47. Ratnakumari L, Qureshi IA, Butterworth RF: Evidence for cholinergic neuronal loss in brain in congenital ornithine transcarbamylase deficiency. Neurosci Lett 1994, 178:63-65.

48. Yonden Z, Aydin M, Kilbas A, Demirin H, Sutcu R, Delibas N: Effects of ammonia and allopurinol on rat hippocampal NMDA receptors. Cell Biochem Funct 2010, 28:159-163.

49. Butterworth RF: Glutamate transporter and receptor function in disorders of ammonia metabolism. Ment Retard Dev Disabil Res Rev 2001, 7:276-279.

50. Lavoie J, Giquère JF, Layrargues GP, Butterworth RF: Amino acid changes in autopsied brain tissue from cirrhotic patients with hepatic encephalopathy. J Neurochem 1987, 49:692-697.

51. Maas A, Brad AS, Walsh PJ: Effects of elevated ammonia concentrations on survival, metabolic rates, and glutamine synthetase activity in the Antarctic pteropod mollusk Clione limacina antarctica. Polar Biol 2012, 35:1123-1128

52. Randall DJ, Tsui TK: Ammonia toxicity in fish. Mar Pollut Bull 2002, 45:17-23.

53. Cooper AJ, Plum F: Biochemistry and physiology of brain ammonia. Physiol Rev 1987, 67:440-519.

54. Cagnon L, Braissant O: Hyperammonemia-induced toxicity for the developing central nervous system. Brain Res Rev 2007, 56:183-197. 
55. Zhou G, Flowers M, Friedrich K, Horton J, Pennington J, Wells MA: Metabolic fate of $\left[{ }^{14} \mathrm{C}\right]$-labeled meal protein amino acids in Aedes aegypti mosquitoes. I Insect Physio/ 2004, 50:337-349.

56. Briegel H, Knüsel I, Timmermann SE: Aedes aegypti: size, reserves, survival, and flight potential. J Vector Ecol 2001, 26:1081-1710.

57. Goldstrohm DA, Pennington JE, Wells MA: The role of hemolymph proline as a nitrogen sink during blood meal digestion by the mosquito Aedes aegypti. J Insect Physiol 2003, 49:115-121.

58. Ruderman NB, Berger $\mathrm{M}$ : The formation of glutamine and alanine in skeletal muscle. J Biol Chem 1974, 249:5500-5506.

doi:10.1186/1756-3305-7-373

Cite this article as: Belloni and Scaraffia: Exposure to L-cycloserine incurs survival costs and behavioral alterations in Aedes aegypti females. Parasites \& Vectors 2014 7:373.

\section{Submit your next manuscript to BioMed Central and take full advantage of:}

- Convenient online submission

- Thorough peer review

- No space constraints or color figure charges

- Immediate publication on acceptance

- Inclusion in PubMed, CAS, Scopus and Google Scholar

- Research which is freely available for redistribution 